\title{
Comparison of perpendicular to the coronal plane versus medial inclination for atlas pedicle screw insertion: an anatomic and radiological study in human cadavers
}

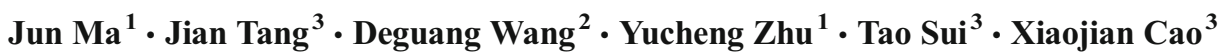

Received: 17 June 2015 / Accepted: 19 July 2015 /Published online: 15 August 2015

(C) The Author(s) 2015. This article is published with open access at Springerlink.com

\begin{abstract}
Purpose To ascertain the anatomic and radiological parameters of the atlas $(\mathrm{C} 1)$ pedicle and to explore a preferable method of $\mathrm{C} 1$ pedicle screw insertion.

Methods Thirty-four conserved human cadaveric cervical spines (20 males, 14 females) underwent computed tomography (CT) scanning. Trajectories P (perpendicular to the coronal plane) and I (with medial inclination) were designed for each $\mathrm{C} 1$ pedicle on $\mathrm{CT}$ images. External pedicle wall width, medullary cavity width, transverse angle, and optimal entry point along each trajectory were measured. Cortical screws of $3.5 \mathrm{~mm}$ in diameter were inserted into $\mathrm{C} 1$ pedicles along trajectory $\mathrm{P}$ and I, respectively, and wall perforation was assessed (post-operative CT scanning).

Results The external pedicle wall width and medullary cavity width along trajectory I were significantly wider than trajectory P $(P<0.01)$. Although external pedicle wall widths were all greater than $3.5 \mathrm{~mm}$, medullary cavity width $<3.5 \mathrm{~mm}$ was found in $16.1 \%$ pedicles along trajectory P and only $2.9 \%$ along trajectory I. Transverse angle was $21.8^{\circ}$ along trajectory $\mathrm{I}$ and $0^{\circ}$ along trajectory P. Optimal entry point of trajectory I
\end{abstract}

Jun Ma, Jian Tang and Deguang Wang contributed equally to this work.

Jun Ma

majun87078@yeah.net

Xiaojian Cao

xiaojiancao001@163.com

1 Department of Orthopedic, Affiliated Suqian Hospital of Xuzhou Medical College, Suqian 223800, Jiangsu, China

2 Department of Human Anatomy, Xuzhou Medical College, Xuzhou 221004, Jiangsu, China

3 Department of Orthopedics, the First Affiliated Hospital of Nanjing Medical University, Nanjing 210029, Jiangsu, China was $4.1 \mathrm{~mm}$ lateral from that of trajectory P. The lateral wall perforation rate was significantly lower along trajectory I than trajectory $\mathrm{P}(P<0.05)$.

Conclusions $\mathrm{C} 1$ pedicle screw trajectory with medial inclination and more lateral entry points yielded wider medullary cavity width than that perpendicular to the coronal plane, and might minimize lateral wall perforation.

Keywords Atlas $\cdot$ Pedicle screw $\cdot$ Trajectory $\cdot$ Computer tomography

\section{Introduction}

The atlantoaxial motion segment is the most mobile region of the entire vertebral column. When destabilised, it is difficult to control the motion of the destabilised $\mathrm{C} 1-\mathrm{C} 2$ segment to achieve a satisfactory fusion [1-3]. The previous studies have reported that nonunion rates for the $\mathrm{C} 1-\mathrm{C} 2$ procedures range from 10 to $30 \%$ and the fusion rate could improve if the $\mathrm{C} 1$ C2 motion could be controlled satisfactorily [4-8]. The most recent techniques for $\mathrm{C} 1$ posterior fixation in upper cervical vertebra stabilisation include lateral mass screws and pedicle screws via the posterior arch and lateral mass. In addition, a previous study has showed that biomechanical stability such as stiffness and pullout strength of a $\mathrm{C} 1$ pedicle screw is superior to that of a lateral mass screw [9]. However, controversy over the transverse direction of the $\mathrm{C} 1$ pedicle screw has existed for a long time [10-12]. Tan et al. [10] suggested that the screw trajectory should be perpendicular to the coronal plane, whereas Ma et al. [11] recommended medial inclination by about $10^{\circ}$, because complications such as neurovascular injury could arise from the lateral mass screw technique $[13,14]$. 
In present study, we designed two trajectories, including trajectory P (trajectory perpendicular to the coronal plane) and trajectory I (trajectory with medial inclination), which were respectively similar to Tan et al.'s and Ma et al.'s methods. Morphological measurements and pedicle screw insertion were performed in order to determine a preferable screw trajectory.

\section{Materials and methods}

\section{Specimens}

Thirty-seven formalin-fixed Chinese cadavers were provided by the Department of Human Anatomy of Xuzhou Medical College. Informed written consents were obtained from donors' relatives. The study was approved by the Institutional Review Board of Xuzhou Medical College (No. XMC01336). Cervical CT scanning for each specimen was performed using a Siemens 128-slice spiral CT scanner (Siemens Medical Solutions, Shanghai, China). Subjects with evidence of fracture, congenital anomalies or structural abnormality of $\mathrm{C} 1$ were excluded. Accordingly, three specimens (two males and one female) were excluded. CT images using 1.0-mm thick slices of the remaining specimens were delivered to the Syngo image workstation (Siemens Medical Solutions, Shanghai, China). Multiplanar reformation (axial, sagittal and coronal plane) was performed on each $\mathrm{C} 1$ pedicle (40 pedicles in 20 males and 28 in 14 females).

\section{Establishment of pedicle screw trajectories}

Two screw trajectories (trajectory $\mathrm{P}$ and I) for each $\mathrm{C} 1$ pedicle were established on CT images as illustrated in Fig. 1. On C1 axial image, the central axis of trajectory $\mathrm{P}$ was parallel to $\mathrm{C} 1$ midline (Fig. 1, left), and that of trajectory I was parallel to the lateral border tangent to the odontoid foramen and vertebral canal of $\mathrm{C} 1$ (Fig. 1, right). The central axis of each trajectory on the sagittal image was modulated through the centre of the posterior arch under the vertebral artery groove.

\section{Pedicle screw insertion method}

The entry point for trajectory P or trajectory I was defined with calipers (Shanghai Drawing Instruments Company, Shanghai, China) according to the pre-operatively measured distance from the posterior tubercle of $\mathrm{C} 1$ to the optimal screw entry point of each trajectory. $\mathrm{C} 1$ posterior tubercle was an obvious anatomical landmark on $\mathrm{CT}$ images or specimens for the measurement of the distance. The cortical bone at the entry point was removed with a grinding drill to reveal the cancellous bone. On the sagittal plane, the entry point was defined at the center of the $\mathrm{C} 1$ posterior lamina cancellous bone.

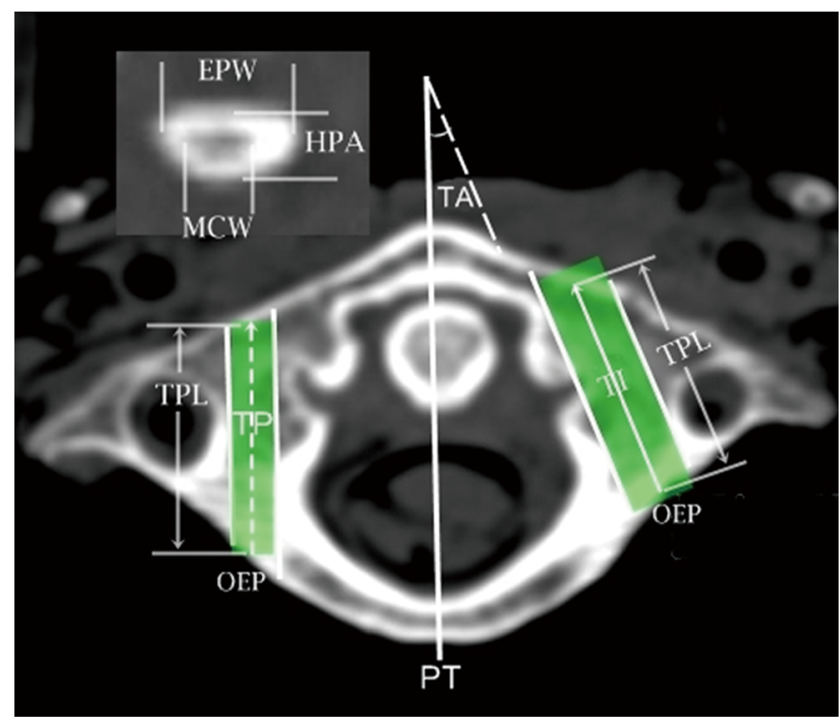

Fig. 1 Trajectory $\mathrm{P}(\mathrm{TP})$ and trajectory $\mathrm{I}(\mathrm{TI})$ of $\mathrm{C} 1$ pedicle and relevant measurements on axial and coronal CT image $T P$ trajectory $\mathrm{P}$ perpendicular to the coronal plane. $T I$ trajectory I parallel to the lateral border tangent of the odontoid foramen and vertebral canal of $\mathrm{C} 1, O E P$ optimal entry point for each trajectory, $P T$ the posterior tubercle of $\mathrm{C} 1$, $T P L$ the total pedicle length, $E P W$ the external mediolateral width at the isthmus of the pedicle, $M C W$ the medullary cavity width at the isthmus of the pedicle, $T A$ the transverse angle of the pedicle screw projection in reference to the midline of $\mathrm{C} 1$

The transverse angle of trajectory $\mathrm{P}$ or trajectory I was guided with a special angular scale combined with an orientation hand (Shanghai Drawing Instruments Company, Shanghai, China) (Fig. 2). The inferior or superior wall of $\mathrm{C} 1$ posterior arch was subperiosteally dissected to determine the sagittal direction of the pedicle screw trajectory (Fig. 3). The pedicle screw could be placed freehand, followed by drilling the predetermined trajectory. Titanium cortical screws of $3.5 \mathrm{~mm}$ in diameter (Xinrong Medical Instrument Company, Suchow, China) were inserted into one side of $\mathrm{C} 1$ pedicle along trajectory $\mathrm{P}$ and the contralateral side along trajectory I.

Relevant parameters (Fig. 1):

1. The distance from the posterior tubercle of $\mathrm{C} 1$ to the optimal screw entry point of each trajectory

2. Transverse angle of trajectory I (Fig. 1, right), with that of trajectory $\mathrm{P}$ on the left being $0^{\circ}$

3. Total pedicle length along each trajectory

4. External pedicle wall width at the isthmus of the pedicle along each trajectory

5. Medullary cavity width at the isthmus of the pedicle along each trajectory

6. Superior-inferior height of the posterior arch under the vertebral artery groove

All assessments were carried out with digital measurement tools in the Syngo image workstation; the averages of the measured values were adopted. 


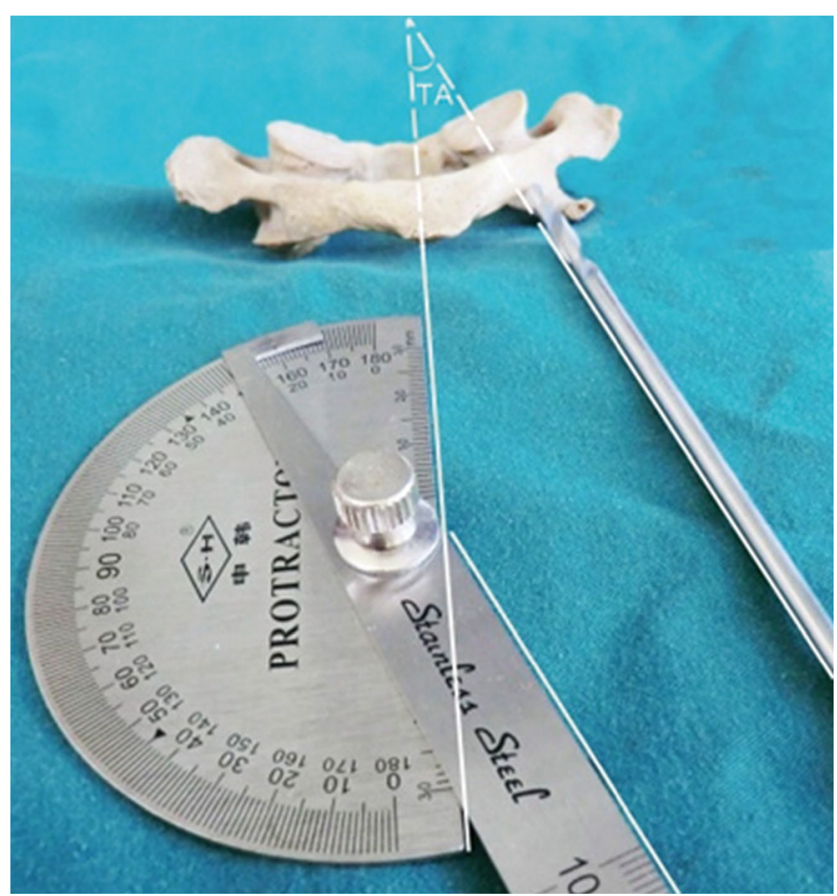

Fig. 2 Guidance of transverse angle (TA) of TI with a special angular scale with an orientation hand. The degree of TA is preset and fixed on the angular scale. While $0^{\circ}$ on the angular scale is set along the sagittal plane of $\mathrm{C} 1$, the orientation hand guides the transverse direction for TI

\section{Evaluation of screw position}

Cervical CT scanning and multiplanar reconstructions were used for evaluation of post-operative screw position by an independent radiologist. The transverse angle of postoperative screw and its deviation degree from pre-operative transverse angle were also measured and calculated. The screw position was attributed one of four grades according to the evaluation criteria of Lee et al. [15]:

Grade 0: the entire screw was placed within the cortical bone of the pedicle.

Grade 1: less than $25 \%$ of screw diameter violation.

Grade $2: 25-50 \%$ of screw diameter violation.

Grade 3: more than $50 \%$ of screw diameter violation.

Grades 0 and 1 were considered to be the correct positions, whereas grades 2 and 3 were considered misplacement. The direction of pedicle screw misplacement was classified as medial, lateral, superior, or inferior. If a screw breached simultaneously two pedicle walls, e.g., the superior-medial wall of $\mathrm{C} 1$ pedicle, the direction of the greatest wall perforation was considered the direction of screw misplacement [16].

\section{Statistics}

Statistical analysis was performed using the software of Statistical Program for Social Sciences 16.0 (SPSS 16.0 for

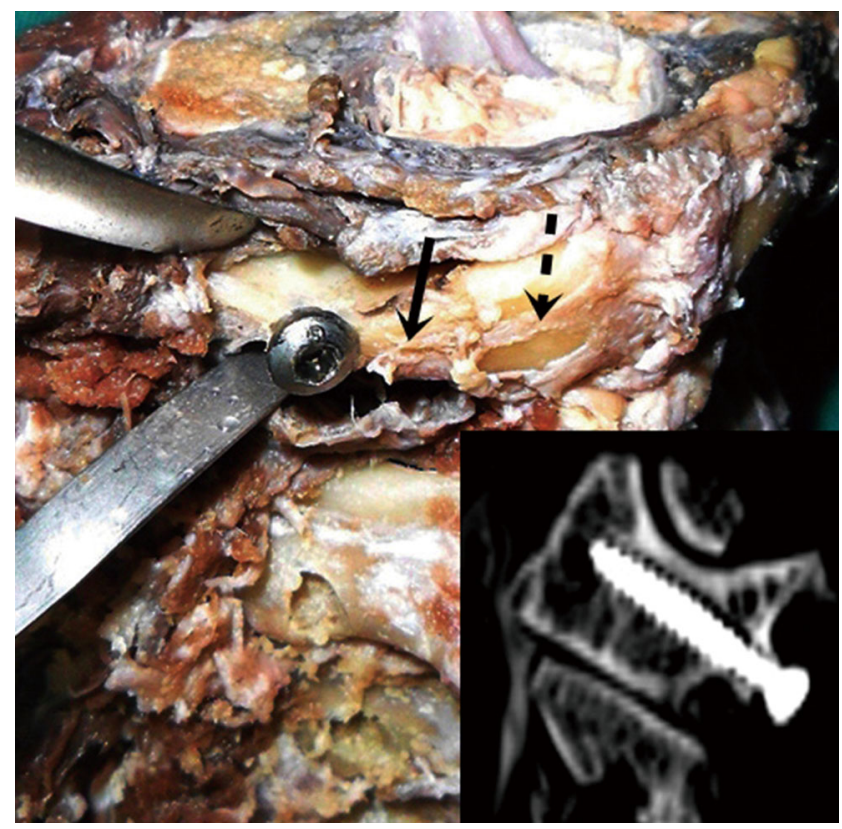

Fig. 3 Posterior view of $\mathrm{C} 1$ lamina and methods of neurovascular preservation along TI. Medial lamina (dotted arrow) is thicker than lateral one (linear arrow). Pedicle screw along TI could be placed without neurovascular injury by exposing superior and inferior wall of $\mathrm{C} 1$ posterior arch with careful subperiosteum stripping. It is difficult along TP because of the thicker lamina and the umbilicate posterior arch

Windows; SPSS, Chicago, IL, USA). C1 pedicle measurement data were displayed as mean \pm SD. Enumerated data were displayed as percentage. Data associated with the $\mathrm{C} 1$ pedicle (the distance from the posterior tubercle of $\mathrm{C} 1$ to the optimal screw entry point, total pedicle length, external pedicle wall width, medullary cavity width, and superior-inferior height of the posterior arch) between trajectories were compared using the paired $t$-test. Male versus female differences were determined with the independent samples $t$-test. The rate of pedicle wall perforation between trajectory $\mathrm{P}$ and trajectory I was compared using the chi-square test.

$P<0.05$ was considered statistically significant.

\section{Results}

\section{Morphological observation of $\mathrm{C} 1$ pedicles on $\mathrm{CT}$ images}

The axial CT images showed that the medial cortex of $\mathrm{C} 1$ pedicle was thicker than the lateral (Fig. 1). On sagittal CT images, the superior surfaces of $\mathrm{C} 1$ posterior arch were flat along trajectory I in all pedicles, but only $17.7 \%$ (12 of 68) along trajectory $\mathrm{P}$. The inferior surface of $\mathrm{C} 1$ posterior arch along each trajectory was smooth (Fig. 4a, b). On the posterior view of $\mathrm{C} 1$, the medial lamina was thicker than lateral, and $\mathrm{C} 1$ lamina became gradually thin laterally (Fig. 3). 
Fig. 4 Sagittal CT images of C1 pedicle along TP and TI. a The superior surface of $\mathrm{C} 1$ posterior arch along TP is umbilicate (dotted arrow). b The superior surface of $\mathrm{C} 1$ posterior arch along $\mathrm{TI}$ is flat (linear arrow)
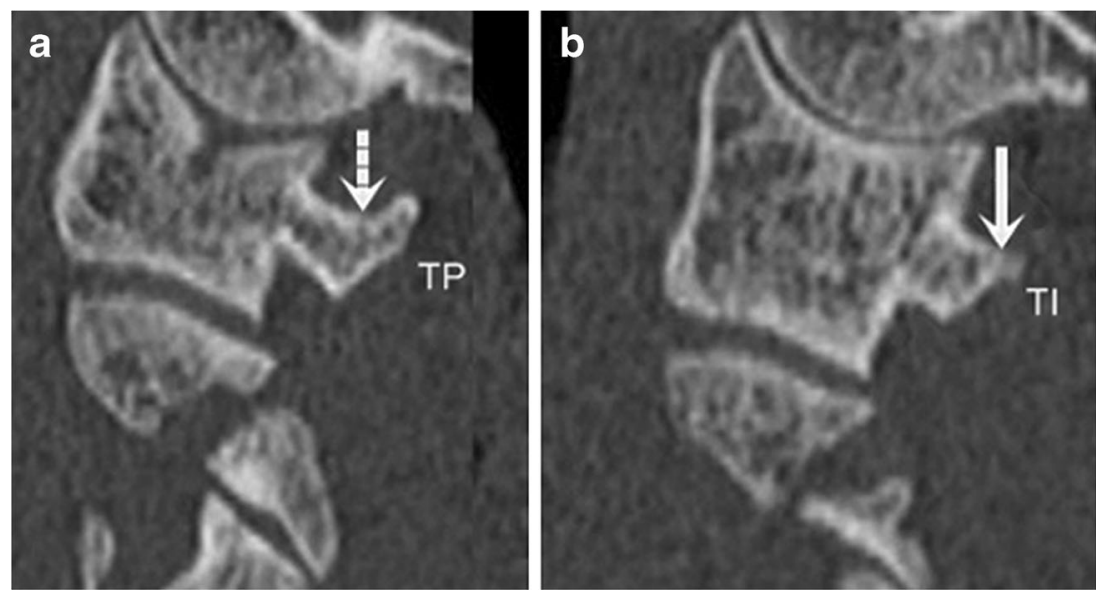

\section{Parameters of $\mathrm{C} 1$ pedicles along each trajectory}

The measurements associated with $\mathrm{C} 1$ pedicle screw insertion along each trajectory are provided in Table 1 . The results demonstrated that external pedicle wall width and medullary cavity width along trajectory I were significantly wider than that along trajectory $\mathrm{P}(P<0.01)$. Although external pedicle wall width along each trajectory was greater than the screw diameter $(3.5 \mathrm{~mm})$, a value of medullary cavity width less than $3.5 \mathrm{~mm}$ was found in $16.1 \%$ (11 of 68 ) pedicles along trajectory P (nine pedicles in females and two in males), but only $2.9 \%$ ( 2 of 68$)$ pedicles along trajectory I (all in females). Transverse angles for $\mathrm{C} 1$ pedicles were averaged $21.8 \pm 8.2^{\circ}$ along trajectory $\mathrm{I}$ and $0^{\circ}$ along trajectory $\mathrm{P}$. The optimal screw entry point of trajectory I was significantly lateral from that of trajectory P. The superior-inferior height of the posterior arch along each trajectory was the same $(4.3 \pm 0.9 \mathrm{~mm})$. Twentytwo percent $(15 / 68)$ of pedicles (including six pedicles in males and nine in females) had superior-inferior height of the posterior arch less than the $3.5 \mathrm{~mm}$ screw diameter. There was no statistically significant difference between trajectories for total pedicle length $(P>0.05)$.

\section{Evaluation of $\mathrm{C} 1$ pedicle screw position and pedicle screw perforation}

Sixty-eight pedicles were successfully inserted with cortical screws, including 34 screws in each (trajectory $\mathrm{P}$ and trajectory I) group (Figs. 3 and 5). Data of post-operative transverse angle, and its deviation degree from preoperative transverse angle, perforation of post-operative C1 pedicle screw were shown in Table 2. The results indicated that post-operative transverse angle along each trajectory deviated from the direction determined pre-operatively. However, there was no significant difference in its deviation degree between trajectory $\mathrm{P}$ and trajectory I $(P>0.05)$. The rate of lateral wall perforation was higher along trajectory $\mathrm{P}$ than trajectory I (29.4\% versus $8.8 \%$, $P<0.05)$. There were no differences between trajectory $\mathrm{P}$ and trajectory $\mathrm{I}$ in the rates of medial, superior or inferior wall perforation $(P>0.05)$.

\section{Discussion}

The technique of $\mathrm{C} 1$ pedicle screw placement was initially developed by Resnick and Benzel [17]: the screw was inserted through the posterior arch or "pedicle" into the lateral mass. Since then, multiple studies have investigated the anatomy and feasibility of $\mathrm{C} 1$ pedicle screw placement [10-12, 18-22]. Most investigations insisted that the mediolateral width at the isthmus of the $\mathrm{C} 1$ pedicle was large enough to insert a $3.5-\mathrm{mm}$ diameter screw [11, 12]. In fact, these authors measured the external pedicle wall width, including the cortex thickness and medullary cavity width of $\mathrm{C} 1$ posterior arch. Gebauer et al. [12] reported that the width of the posterior arch at the vertebral artery (VA) groove was $9.8 \pm 1.7 \mathrm{~mm}$ for males and $8.9 \pm 0.7 \mathrm{~mm}$ for females. Meanwhile, Ma et al. [11] found that it was on average $8.46 \pm 0.57 \mathrm{~mm}$. In our research, external pedicle wall width along trajectory $\mathrm{P}$ was $9.3 \pm 1.5 \mathrm{~mm}$ for males and $7.0 \pm 1.6 \mathrm{~mm}$ for females, also greater than $3.5-\mathrm{mm}$ or 4.0-mm screw diameter, in agreement with the studies published by Gebauer et al. and Ma et al. The external pedicle wall width along trajectory I was even greater than that along trajectory $\mathrm{P}$, due to larger available mediolateral width.

However, it has been demonstrated that the stability of cervical pedicle screw largely depends on the internal characteristics of the pedicle, and not so much on its external dimensions [23]. Unfortunately, reports on the $\mathrm{C} 1$ pedicle's medullary cavity width are scarce. In recent years, multiplanar CT renders possibility of the precise measurement of the inner as well as outer pedicle diameters [24]. Measurement of C1 pedicle's medullary cavity width on axial CT image is becoming 
more and more important for choosing an optimal trajectory, and evaluating the safety of $\mathrm{C} 1$ pedicle screw trajectory.

Different from sub-axial cervical vertebra, the vertebral canal of $\mathrm{C} 1$ consists of two parts, which contains the odontoid process and the spinal cord. So we designed two trajectories named trajectory $\mathrm{P}$ and trajectory I for $\mathrm{C} 1$ pedicle screw insertion. As demonstrated above, the rate of lateral wall perforation was higher along trajectory $\mathrm{P}(29.4 \%)$ than trajectory I $(8.8 \%)$. Two reasons could explain these differences. First, the medullary cavity width along trajectory $\mathrm{P}$ is lesser than that along trajectory I by $1.4 \mathrm{~mm}$; in addition, medullary cavity width $<3.5 \mathrm{~mm}$ was found in $16.1 \%$ of pedicles along trajectory P, and only $2.9 \%$ along trajectory I. Another reason is that the lateral wall of $\mathrm{C} 1$ pedicle is thinner than the medial wall, similar to sub-axial cervical vertebra [23-25]. As a result, the lateral wall perforation is more frequent than the medial one. If trajectory $\mathrm{P}$ is not wide enough to contain a pedicle screw, trajectory I would be a better choice. In fact, any trajectory with entry points from trajectory P to trajectory I and introversion direction from parallel to $\mathrm{C} 1$ midline to parallel to the lateral border tangent to the odontoid foramen and vertebral canal of $\mathrm{C} 1$ could insert pedicle screw. If a trajectory with small transverse angle could not contain a $3.5-\mathrm{mm}$ diameter pedicle screw, more adequate introversion of the transverse angle with more lateral entry points could make a wider medullary cavity width in order to minimize the risk of lateral wall perforation. The individual maximum medial inclination angle might be transverse angle of trajectory I measured preoperatively on CT images.

Numerous studies have indicated that the limited superiorinferior height of $\mathrm{C} 1$ posterior arch under the vertebral artery groove restricts $\mathrm{C} 1$ pedicle screw application [18-20]. If the height is less than 3.5 or $4.0 \mathrm{~mm}$ screw diameter, the superior or inferior wall would be penetrated during screw placement. Our research demonstrated that the superior-inferior height of the posterior arch under the vertebral artery groove was $4.3 \pm$ $0.9 \mathrm{~mm}$, which was similar to data reported by Ma et al. [18] and Qian et al.[19] The superior-inferior height of the posterior arch $<3.5 \mathrm{~mm}$ screw diameter was found $22.0 \%(15 / 68)$ of pedicles. However, the main handicap to $\mathrm{C} 1$ pedicle screw insertion was injury of the VA running along the vertebral artery groove, or venous plexus and C2 nerve root. Deviant direction of pedicle screw insertion on sagittal plane would result in penetration of the posterior arch even with superiorinferior height of the posterior arch larger than screw diameter. We took a measurement to prevent injury of the neurovascular structure. Superior and inferior wall of $\mathrm{C} 1$ posterior arch could be subperiosteally dissected. Then, the direction of $\mathrm{C} 1$ pedicle on sagittal plane was evident. Drilling holes along the $\mathrm{C} 1$ pedicle trajectory and screw insertion could be performed following this direction.

Many researchers agreed that the $\mathrm{C} 1$ posterior arches could be divided into four different categories: superficial groove, 
Fig. 5 a Post-operative CT images of $\mathrm{C} 1$ pedicles screw along TP and TI. The right screw along TP perforates the lateral wall of $\mathrm{C} 1$ pedicle. The left screw along TI is fully in the pedicle without perforation. $\mathbf{b}, \mathbf{c}$ Post-operative anteriorposterior and lateral $\mathrm{X}$-rays of $\mathrm{C} 1$ pedicles screw. The right screw along TP and the left along TI

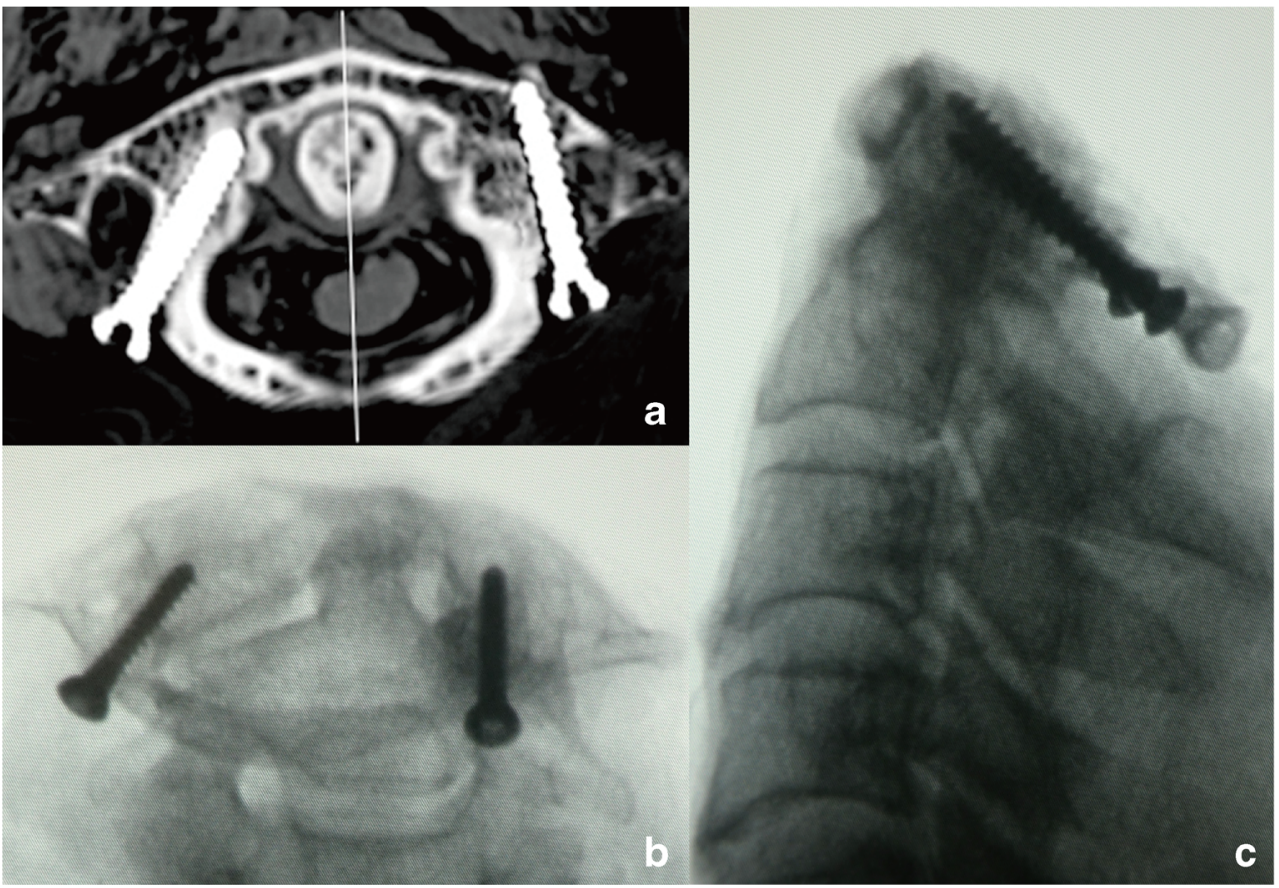

deep groove, semi-foramen-shaped, and foramen-shaped [18, 21]. In the latter three categories, the superior wall of the posterior arch is difficult to be subperiosteally dissected. However, we found that the superior wall of the $\mathrm{C} 1$ posterior arch was flat along trajectory I and groove-shaped along trajectory $\mathrm{P}$, likely because the $\mathrm{C} 1$ lamina became gradually thin laterally (Fig. 3). This was in agreement with Kim et al. [22], who showed that orientation of $\mathrm{C} 1$ lamina was changed from vertical to horizontal direction in the posterior view. Therefore, exposure of the superior wall of the $\mathrm{C} 1$ posterior arch by subperiosteum dissection was easier along trajectory I than trajectory P. Inferior wall of $\mathrm{C} 1$ posterior arch could also be subperiosteally dissected. They were useful to determine sagittal direction of pedicle screw insertion and avoid inferior or superior wall perforation.

Several limitations of the current study should also be mentioned. Limited to the number of cadavers, the data of the study are primarily used only as a reference. More measurements could be taken to minimize the deviation of $\mathrm{C} 1$ pedicle screw insertion from preoperatively determined direction on

Table 2 Transverse angle of post-operative screw and pedicle screw position

\begin{tabular}{|c|c|c|c|c|c|c|}
\hline & \multicolumn{2}{|l|}{ Male $(n=20)$} & \multicolumn{2}{|l|}{ Female $(n=14)$} & \multicolumn{2}{|l|}{ Total $(n=34)$} \\
\hline & $\begin{array}{l}\text { Trajectory } \\
\mathrm{P} \text { (range) }\end{array}$ & $\begin{array}{l}\text { Trajectory } \\
\text { I (range) }\end{array}$ & $\begin{array}{l}\text { Trajectory } \\
\mathrm{P} \text { (range) }\end{array}$ & $\begin{array}{l}\text { Trajectory } \\
\text { I (range) }\end{array}$ & $\begin{array}{l}\text { Trajectory } \\
\mathrm{P} \text { (range) }\end{array}$ & $\begin{array}{l}\text { Trajectory } \\
\text { I (range) }\end{array}$ \\
\hline $\begin{array}{l}\text { Transverse angle of } \\
\text { post-operative screw }\left(^{\circ}\right)\end{array}$ & $4.1 \pm 2.8(1.5-13.5)$ & $18.8 \pm 4.0(12.0-27.3)$ & $4.3 \pm 2.7(2.0-11.5)$ & $20.2 \pm 4.7(12.5-30.2)$ & $4.2 \pm 2.7(1.5-13.5)$ & $19.5 \pm 4.3(12.0-30.2)$ \\
\hline $\begin{array}{l}\text { Degrees of deviation } \\
\text { from pre-operative } \\
\text { transverse angle }\left(^{\circ}\right)\end{array}$ & $4.1 \pm 2.8(1.5-13.5)$ & $4.1 \pm 2.3(1.8-11.1)$ & $4.3 \pm 2.7(2.0-11.5)$ & $4.6 \pm 2.1(1.4-11.6)$ & $4.2 \pm 2.7(1.5-13.5)$ & $4.3 \pm 2.1(1.4-11.6)$ \\
\hline Grade 0 & $35.0 \%(7 / 20)$ & $55 \%(11 / 20)$ & $14.2 \%(2 / 14)$ & $28.5 \%(4 / 14)$ & $26.4 \%(9 / 34)$ & $44.1 \%(15 / 34)$ \\
\hline Grade 1 & $35.0 \%(7 / 20)$ & $30.0 \%(6 / 20)$ & $14.2 \%(2 / 14)$ & $35.7 \%(5 / 14)$ & $26.4 \%(9 / 34)$ & $32.3 \%(11 / 34)$ \\
\hline Grade 2 & $25.0 \%(5 / 20)$ & $10.0 \%(2 / 20)$ & $50.0 \%(7 / 14)$ & $28.5 \%(4 / 14)$ & $35.3 \%(12 / 34)$ & $17.6 \%(6 / 34)$ \\
\hline Grade 3 & $5.0 \%(1 / 20)$ & $5.0 \%(1 / 20)$ & $21.4 \%(3 / 14)$ & $7.1 \%(1 / 14)$ & $11.7 \%(4 / 34)$ & $5.9 \%(2 / 34)$ \\
\hline Lateral wall perforation & $15.0 \%(3 / 20)$ & $5.0 \%(1 / 20)$ & $50.0 \%(7 / 14)$ & $14.2 \%(2 / 14)$ & $29.4 \%(10 / 34) *$ & $8.8 \%(3 / 34)$ \\
\hline Medial wall perforation & 0 & 0 & 0 & 0 & 0 & 0 \\
\hline Superior wall perforation & $10.0 \%(2 / 20)$ & $5.0 \%(1 / 20)$ & $7.1 \%(1 / 14)$ & $14.2 \%(2 / 14)$ & $8.8 \%(3 / 34)$ & $8.8 \%(3 / 34)$ \\
\hline Inferior wall perforation & $5.0 \%(1 / 20)$ & $5.0 \%(1 / 20)$ & $14.2 \%(2 / 14)$ & $17.1 \%(1 / 14)$ & $8.8 \%(3 / 34)$ & $5.9 \%(2 / 34)$ \\
\hline
\end{tabular}

$* P<0.05$, versus TI 
CT images. In addition, clinical researches need to be performed on the safety and possibility of pedicle screw insertion along different trajectories.

\section{Conclusion}

$\mathrm{C} 1$ pedicle screw trajectory with more medial inclination of the transverse angle and more lateral entry points could make a wider medullary cavity compared with the trajectory perpendicular to the coronal plane. The maximum medial inclination might be the transverse angle of trajectory I measured preoperatively on CT images. Neurovascular injury could be avoided by exposing the superior and inferior walls with careful subperiosteum dissection.

Acknowledgments This work was supported by National Natural Science Foundation of China (No. 81371968), and the Foundation of Jiangsu Province Public Health Bureau of China (No. BK2012718).

\section{Conflict of interest None.}

Open Access This article is distributed under the terms of the Creative Commons Attribution 4.0 International License (http:// creativecommons.org/licenses/by/4.0/), which permits unrestricted use, distribution, and reproduction in any medium, provided you give appropriate credit to the original author(s) and the source, provide a link to the Creative Commons license, and indicate if changes were made.

\section{References}

1. Dickman CA, Sonntag VK (1995) Surgical management of atlantoaxial nonunions. J Neurosurg 83(2):248-253. doi:10.3171/ jns. 1995.83.2.0248

2. Grob D, Crisco JJ 3rd, Panjabi MM, Wang P, Dvorak J (1992) Biomechanical evaluation of four different posterior atlantoaxial fixation techniques. Spine 17(5):480-490

3. Montesano PX, Juach EC, Anderson PA, Benson DR, Hanson PB (1991) Biomechanics of cervical spine internal fixation. Spine 16(3 Suppl):S10-S16

4. Glynn MK, Sheehan JM (1983) Fusion of the cervical spine for instability. Clin Orthop Relat Res 179:97-101

5. Fielding JW, Hensinger RN, Hawkins RJ (1980) Os Odontoideum. J Bone Joint Surg Am 62(3):376-383

6. Griswold DM, Albright JA, Schiffman E, Johnson R, Southwick W (1978) Atlanto-axial fusion for instability. J Bone Joint Surg Am 60(3):285-292

7. Husby J, Sorensen KH (1974) Fracture of the odontoid process of the axis. Acta Orthop Scand 45(2):182-192

8. Schatzker J, Rorabeck CH, Waddell JP (1971) Fractures of the dens (odontoid process). An analysis of thirty-seven cases. J Bone Joint Surg Br 53(3):392-405

9. Ma XY, Yin QS, Wu ZH, Xia H, Liu JF, Xiang M, Zhao WD, Zhong SZ (2009) C1 pedicle screws versus C1 lateral mass screws: comparisons of pullout strengths and biomechanical stabilities. Spine 34(4):371-377. doi:10.1097/BRS.0b013e318193a21b
10. Tan M, Wang H, Wang Y, Zhang G, Yi P, Li Z, Wei H, Yang F (2003) Morphometric evaluation of screw fixation in atlas via posterior arch and lateral mass. Spine 28(9):888-895. doi:10.1097/01. brs.0000058719.48596.cc

11. Ma XY, Yin QS, Wu ZH, Xia H, Liu JF, Zhong SZ (2005) Anatomic considerations for the pedicle screw placement in the first cervical vertebra. Spine 30(13):1519-1523

12. Gebauer M, Barvencik F, Briem D, Kolb JP, Seitz S, Rueger JM, Puschel K, Amling M (2010) Evaluation of anatomic landmarks and safe zones for screw placement in the atlas via the posterior arch. Eur Spine J 19(1):85-90. doi:10.1007/s00586-009-1181-8

13. Squires J, Molinari RW (2010) C1 lateral mass screw placement with intentional sacrifice of the $\mathrm{C} 2$ ganglion: functional outcomes and morbidity in elderly patients. Eur Spine J 19(8):1318-1324. doi:10.1007/s00586-010-1452-4

14. $\mathrm{Hu}$ Y, Kepler CK, Albert TJ, Yuan ZS, Ma WH, Gu YJ, Xu RM (2013) Accuracy and complications associated with the freehand C1 lateral mass screw fixation technique: a radiographic and clinical assessment. J Neurosurg Spine 18(4):372-377. doi:10.3171/2013. 1.spine 12724

15. Lee SH, Kim KT, Suk KS, Lee JH, Son ES, Kwack YH, Oh HS (2012) Assessment of pedicle perforation by the cervical pedicle screw placement using plain radiographs: a comparison with computed tomography. Spine 37(4):280-285. doi:10.1097/BRS. 0b013e31822338ad

16. Nakashima H, Yukawa $\mathrm{Y}$, Imagama S, Kanemura T, Kamiya M, Yanase M, Ito K, Machino M, Yoshida G, Ishikawa Y, Matsuyama Y, Ishiguro N, Kato F (2012) Complications of cervical pedicle screw fixation for nontraumatic lesions: a multicenter study of 84 patients. J Neurosurg Spine 16(3):238-247. doi:10.3171/2011.11. spine 11102

17. Resnick DK, Benzel EC (2002) C1-C2 pedicle screw fixation with rigid cantilever beam construct: case report and technical note. Neurosurgery 50(2):426-428

18. He F, Yin Q, Zhao T (2008) Classification of atlas pedicles and methodological study of pedicle screw fixation. Zhongguo Xiu Fu Chong Jian Wai Ke Za Zhi 22(8):905-909

19. Qian LX, Hao DJ, He BR, Jiang YH (2013) Morphology of the atlas pedicle revisited: a morphometric CT-based study on 120 patients. Eur Spine J 22(5):1142-1146. doi:10.1007/s00586-0132662-3

20. Huang DG, He SM, Pan JW, Hui H, Hu HM, He BR, Li H, Zhang $\mathrm{XF}$, Hao DJ (2014) Is the $4 \mathrm{~mm}$ height of the vertebral artery groove really a limitation of $\mathrm{C} 1$ pedicle screw insertion? Eur Spine J 23(5): 1109-1114. doi:10.1007/s00586-014-3217-y

21. Pei-Feng J, Li-Ping W, Ji-Hong F, Yi-Kai L, Manas D (2011) Morphological asymmetry of the atlas and its clinical implications. J Manip Physiol Ther 34(7):463-467. doi:10.1016/j.jmpt.2011.05. 003

22. Kim JH, Kwak DS, Han SH, Cho SM, You SH, Kim MK (2013) Anatomic consideration of the $\mathrm{C} 1$ laminar arch for lateral mass screw fixation via $\mathrm{C} 1$ lateral lamina: a landmark between the lateral and posterior lamina of the C1. J Kor Neurosurg Soc 54(1):25-29. doi:10.3340/jkns.2013.54.1.25

23. Panjabi MM, Shin EK, Chen NC, Wang JL (2000) Internal morphology of human cervical pedicles. Spine 25(10):1197-1205

24. Reinhold M, Magerl F, Rieger M, Blauth M (2007) Cervical pedicle screw placement: feasibility and accuracy of two new insertion techniques based on morphometric data. Eur Spine J 16(1):47-56. doi:10.1007/s00586-006-0104-1

25. Neo M, Sakamoto T, Fujibayashi S, Nakamura T (2005) The clinical risk of vertebral artery injury from cervical pedicle screws inserted in degenerative vertebrae. Spine 30(24):2800-2805 